\title{
What can we expect from corporate reporting? The case of Croatia
}

\begin{abstract}
We have been noticing a remarkable growth in corporate reporting today, as well as efforts made at harmonising reporting standards. Corporate reports have become a real means for disseminating sensitive information to various stakeholders in order to enhance corporate transparency. This article aims to enlighten the status of corporate reporting in limited liability joint stock companies in the Republic of Croatia, as well as to underline future trends in corporate reporting. Analysis based on the field research, which was conducted in the first half of 2010, shows that Croatian corporations are lagging behind their counterparts from developed nations, but have started to recognise the importance of social and environmental disclosure.
\end{abstract}

Keywords: corporate reporting, current and future trends, Republic of Croatia, corporate social responsibility

Introduction

Everything significant that is happening in organisations involves communications, but communication is often interrupted by hierarchical structures, power and status differences, rules, etc. Communication in organisation is not a natural process, but is constructed from a perspective which represents management interests - especially in the area of corporate reporting (Buchanan and Huczynski, 2010: 228). Other than financial reports, companies are nowadays obliged, if not by law then by their stakeholders, to provide non-financial reports which cover intellectual property, human capital, the environment, customers, corporate reputation, human rights and anti-corruption practices. Corporate reporting is the most important part of corporate communications which can consolidate and enhance the sense of confidence among all stakeholders (Subhasis and Subhrajyoti, 2009: 102). As such, it is used by companies as a platform for showcasing their achievements against their promises, as well as for clarifying the model for success and the key relationships (internal and external) that facilitate success. In the future, corporate reporting should provide a credible, realistic and coherent picture of a company's performance.

The field research for this study was carried out in the first half of 2010 on a sample of 100 randomly selected joint-stock limited liability corporations. The questionnaire was sent by e-mail to responsible managers, according to a database provided by the Croatian Chamber of Commerce. The return rate was $30 \%$ and, among the surveyed corporations, $15.4 \%$ were small; $38.5 \%$ medium-sized; and $46.2 \%$ large corporations (under Article 16 of the Croatian Accounting Law (NN 90/92)). Of these corporations, $52.2 \%$ were listed on the Zagreb Stock Exchange. 
The aim of this article is to review the status of corporate reporting in these corporations, as well as to underline future trends in the area. Despite the (worldwide) improvements in the scope of reported information, our research showed that Croatian corporations have not achieved the level of reporting of developed countries, primarily because of the country's stage of development and culture as well as the level of regulation, which has a great influence on corporate reporting.

\section{About corporate reporting}

Corporate reporting is the primary means by which corporate entities provide details of corporate performance to their various stakeholders, not least the investment community (Everingham and Kana, 2008). It is a vital ingredient in their ability to motivate ongoing stakeholder support for and commitment to the organisation. However, corporate reporting communication is a one-way process and has great influence on the decision-making process, so significant attention must be paid to each of the following:

- filtering - distorted information

- corporate status

- time

- value judgements - which are made by a receiver

- source credibility - which should be developed over the years and which refers to trust and ethics.

Corporate reporting relates to the presentation and disclosure aspects of the following areas of reporting (PricewaterhouseCoopers website on corporate reporting):

1. financial reporting - both financial statements and accompanying notes

2. corporate governance - the communication of processes by which companies are directed and controlled (i.e. information on board composition and development, accountability and audit, and relations with stakeholders)

3. executive remuneration - communications on how executives are remunerated, both in the short- and the longer-term

4. corporate social responsibility - communications on how companies are understanding and managing their impact on people, clients, suppliers, society, and the environment in order to deliver increased value to all stakeholders

5. narrative reporting.

On the other hand, companies themselves have different purposes for these reports, including enhanced public relations, internal measurements and support for strategic goals and thought-leadership within their industries (sustainabledictionary.com). Many companies have determined that the brand-building and promotional benefits to declaring these activities and accomplishments outweigh the costs associated with tracking, generating and disclosing them. For this purpose, corporations publish their reports. Financial reports and other impersonal documents represent the leanest media because they allow only one form of data transmission - the written - and the sender does not receive timely feedback from the receiver (McShane and von Glinow, 2005: 332). The exchange of information is standardised for all. Publicised information to all stakeholders is usually available through annual, sustainability and integrated reports, as well as the so-called One Report. 
Annual reports are the main basis for disseminating real information to various stakeholders, particularly to shareholders and investors, but they have recently been supplemented with several social and environmental issues or 'stand-alone' full coverage sustainability reports.

These reports, covering social and environmental corporate concerns, contain data on rather sensitive issues, such as enterprise-employee relations, human rights, respect for the environment, consumer protection issues and community involvement. Investors and other stakeholders are increasingly interested in how corporations perform in terms of environmental, social and governance issues, rather than focusing solely on economic elements. This is to say that stakeholders are demanding the 'provision of an ethical, social and environmental account' as well as a financial one (Adams, 2004: 732). Sustainability reports seek to build a thriving relationship and represent corporate investment in trust, transparency, honesty and respect for stakeholders.

This has also led to the emergence today of integrated reports. Integrated reports contain both the annual and the sustainability reports, but the scope of these reports is (PricewaterhouseCoopers, 2010: 39):

- market context (industry, economic, political, regulatory)

- strategy and governance

- remuneration

- business model and supply chain (customers, suppliers and communities)

- risk and risk management

- human resources (diversity, well-being, retention, absenteeism, etc.)

- physical resources (energy, water, scarce resources)

- emissions

- government payments/receipts

- other community impacts and contributions

- key performance indicators covering all above.

However, there are also those who support the One Report method as one strategy of integrated reporting (Eccles and Krzus, 2010: 14). Integrating reporting in the context of One Report means to describe, simply and clearly, management's view of the relationships between financial and non-financial metrics. Eccles and Krzus argue that there are four key benefits of integrated reporting: greater clarity about the relationship between financial and non-financial key performance indicators; better management decisions; deeper engagement with the broad stakeholder community; and lower reputation risk. However, KPMG points out that integrated reporting is different from a One Report (annual) approach, which assumes that all relevant stakeholders can fulfil their information needs with this single report (KPMG, 2010: 5).

However, in practice companies have started to use narrative reporting as shorthand for the critical contextual and non-financial information that is reported alongside financial information so as to provide a broader understanding of a company's business, its market position, strategy, performance and future prospects - including quantified metrics.

An effective corporate reporting framework should include: a market overview; a detailed explanation of how the company intends to compete in the market place; a report on financial performance benchmarked against competitors and peers; and an 
assessment of the company's management of its tangible and intangible assets (Chambers, 2003). Corporate reports are used today to enhance corporate transparency and enable managers and investors to make sensitive economic decisions. Every decision has a social consequence because a corporation makes up a part of society and has extensive power. In the light of this, corporate reporting is an important communications channel through which corporations may disseminate valuable information to many stakeholders, thus building trust between management and other stakeholders. Social disclosure is a strategic plan by a corporation to highlight a firm's social performance to its stakeholders (Roberts, 1992).

\section{Developments in corporate reporting - a historical note and ongoing trends}

Corporations traditionally report financial information. Due to the changes happening in the surrounding environment, and under the influence of different factors (i.e. regulation, technological change supported by globalisation and further demographic changes) which have had an enormous impact on organisations and which have led to changes in organisational structures, corporate reporting has evolved.

Corporate reporting has undergone a rapid evolution since the first environmental reports appeared. Environmental issues have been joined on the agenda in the last decade by social considerations. The first part of the decade was marred by corporate scandals (i.e. Enron and WorldCom) and companies came under scrutiny for dubious accounting practices as well as corporate governance approaches. Thus regulators, financial analysts, consumers, employees and other relevant stakeholders have all contributed to the creation of milestones in corporate reporting - by demanding better ways of tracking the real value of a corporation.

The trend towards sustainability reporting has been witnessing extreme growth in recent years. Basically, thanks to corporate endeavour, global reporting leaders have worked hard in order to identify and communicate performance on material issues and to demonstrate how sustainability is being integrated into corporate strategy to deliver against environmental, social and economic expectations. KPMG's triennial surveys of international corporate responsibility reporting practices revealed that, in 2002, approximately one-third of its sample of top 100 companies had incorporated social (and economic) issues into what had been previously a purely environmental report; by 2005 , the proportion had grown to almost one-half(Owen and O'Dwyer, 2009: 394). In 2008, the KPMG survey revealed that, amongst 250 global corporations, $79 \%$ published stand-alone corporate social responsibility reports; this is a dramatic rise in reporting since 2005 , when $52 \%$ of corporations published such stand-alone reports (KPMG, 2008).

The next stage of reporting developments is headed towards integrated reporting a single report but also representing an ongoing reporting relationship: it is as much about listening as talking and emphasises the creation of a collective conversation between the company and its stakeholders. There have been several initiatives in the area of developing integrated reports. In 2009, more than 160 corporations globally published integrated reports (Corporate Register, 2010), but this is an ongoing process and needs to be further developed. 
In this direction, some of responsible investment's best-known names, such as APG, the UN Principles for Responsible Investment, Railpen and the International Corporate Governance Network, have been involved in a new group looking at how to integrate ESG (environmental, social and governance) factors into corporate reporting. The International Integrated Reporting Committee (IIRC), composed of a Working and a Steering Group, was launched on 2 August 2010 by the Global Reporting Initiative and Prince Charles's Accounting for Sustainability Project. This is the latest initiative to grapple with the topic of how to integrate sustainability and financial reporting (Responsible Investor website).

An integrated report should contain (PricewaterhouseCoopers, nd):

1. annual financial statements

2. directors' report

3. directors' statement of responsibility

4. management and directors' commentary

5. report of the audit committee

6. sustainability report

7. risk disclosures

8. IT reporting

9. remuneration report

10. statement by the company secretary

11. terms of reference of committees

12. ethics statement.

Evidently, the structure and adoption of these reports will vary from country to country as it is a matter of cultural diversity and they are, of course, subject to the main responsibility of the board of directors. After a meeting of twenty leading organisations in December 2009, KPMG (2010: 5) announced the following conclusion:

Integrated reporting is the way forward in corporate reporting.

As such, it is only the step in developing globally harmonised corporate reports.

Europe was always a leader in corporate reporting (it was the first region to produce environmental reports, about twenty years ago), followed by north America (despite the legislative initiatives (i.e. the Liability Act) focused on mandatory environmental and pollution disclosures) and Asia (Corporate Register, 2010: 4). Corporations in Japan have topped the table in rates of corporate responsibility reporting. In 2008, $88 \%$ of corporations in Japan published 'stand-alone' corporate social responsibility reports, followed by United Kingdom with $84 \%$, United States with $73 \%$, Canada with $60 \%$ and Sweden with $59 \%$ of corporations. In the same year, $22 \%$ of Brazilian corporations, $21 \%$ of corporations in Switzerland, $19 \%$ in South Africa, $12 \%$ in Norway and in France, $8 \%$ in Australia, $7 \%$ in UK and $5 \%$ in Japan published integrated reports (corporate social responsibility reports within annual reports) (KPMG, 2008: 16).

Corporate reporting is still evolving, which company managements must take into consideration, asking themselves the following questions (Everingham and Kana, 2008): 
1. Who are we reporting to?

2. Why do they need the information?

3. What information do they need?

4. When do they need it?

5. How do they wish to receive it?

Changes in managerial structures which are encouraged by the new approaches in corporate governance place further requirements on corporate reporting. We can distinguish three different strands (Coombes and Wong, 2004: 4):

1. the need to increase the transparency of corporate performance

2. common global accounting standards

3. the extent to which corporate reporting is actually measuring, even in principle, the full dimension of corporate performance, particularly as developed economies increasingly move away from asset-intensive industries.

The corporate reporting supply chain must always be taken into account (DiPiazza and Eccles, 2002). This always begins with the company executives, who are responsible for building and developing ethical business government. The first challenge for companies, after the scandals - of Parmalat (Italy); Podravka (Croatia) etc. - is to build trust and to make stakeholders believe in the corporation's goals, principles and governance. However, new reporting approaches are not focused only on corporate reputations - they influence corporate value; societal culture; corporate culture; and internal stakeholders, i.e. employees which will assure the fulfilment of the strategy. Trends in corporate reporting will almost certainly go through the following stages: building trust - transparency; narrative reporting; taking advantage of new technologies for information distribution - online media; market regulations; industry specialised reports; and the development of internal communications to assure better external communications.

\section{What's going on in Croatia?}

Not so many research studies have aimed to discover the reporting practices conducted in the Republic of Croatia. Nevertheless, the studies that do exist either cover only publicly listed corporations' attitudes towards reporting (Koričan and Ćorić) or are focused solely on financial reporting (Pervan, 2007).

For joint stock limited liability corporations which are listed on the Zagreb Stock Exchange in Croatia, corporate reporting is a critical source of information which influences share price, reputation, environmental acceptance, etc. (Zagreb Stock Exchange, 2010). This is usually carried out via the company's internet page, and most of the information that can be found there is constituted from the annual, half-yearly and quarterly financial reports. Accordingly, the annual report should contain:

1. audited annual financial statements - made by using the appropriate standards of financial reporting - give a complete and truthful statement of assets and liabilities; losses and profits; financial situation; business performance; and any companies whose results are consolidated

2. management report - which contains a truthful statement of business developments and results, as well as the condition of the issuer of the shares and any others whose results are consolidated 
3. statement - a description of the most significant risks and uncertainties to which the company is exposed made by those responsible for compiling the annual report, and to the best of their knowledge, listing their first and family name, position and duties.

The half-yearly report should contain:

1. an abridged set of half-yearly financial statements

2. management's interim report

3. a statement by those responsible for compiling the half-yearly report, listing names, position and duty as above, and again with a reference to this being made to the best of their knowledge.

The quarterly report should be disclosed to the public as soon as possible, and no later than thirty days from the last day of the quarter to which it refers, and should continue to be available to the public for at least five years from the day of its publication (Zagreb Stock Exchange, 2011). Information may be missing about forecast results, realised strategic objectives, possible risks, etc. although, according to the regulations:

All information which might have some influence on decision making on investment in securities of the company have to be announced immediately and simultaneously to all persons who might be interested therein, including to the equal extent both positive and negative information, with the objective to enable the information receiver to acquire complete understanding and correct assessment of the company's situation. (Zagreb Stock Exchange, 2010)

This enlightens that the regulations imposed by the state are not proceeding in line with current trends in reporting (especially integrated reporting, where the information presented should be wider and based on more constructive elements). Corporations are obliged to prepare and publish financial statements in compliance with International Financial Reporting Standards, taking into account contemporary international trends in financial reporting and market requirements. Moreover, every entrepreneur incorporated in Croatia is obliged to conduct accounting records and prepare financial statements according to accounting principles so that information about the operations and position of the assets of the business may be made available. After January 2008, according to the Accounting Law, very detailed conditions for external reporting have now been defined (Republic of Croatia, 2007). Accordingly, all large- and mediumlarge entrepreneurs organised as joint stock companies are obliged to disclose financial statements publicly. Financial statements are disclosed according to the content of the balance sheet and income statement, prescribed as for small entrepreneurs.

Once a year, the financial reports of all large and medium-large entrepreneurs, if organised as joint stock companies, must be audited. Small entrepreneurs organised as joint stock companies are liable to make a shortened audit report - essentially, a review of operations - every third year. Other small and medium-large entrepreneurs are obliged to audit financial reports according to their own regulations or to statute. However, what is actually happening in practice?

When focusing on corporate reporting, we are entering into the field of corporate communications. According to our research, a majority of respondents highlighted a preference for written communications, often constructed from a perspective which 
represents management's interests. As such, it is the ethical dimension of management that is influencing the presented reports.

Our results show that neutral factors are transparency of information and improvisation, although we evaluate generally that, in the Croatian business environment, missing aspects are, principally: responsibility (2.66); honesty (2.77); and transparency (2.88). In light of this, there is a question of how we may comprehend corporate reports.

Some $91.7 \%$ of Croatian corporations publicly disclose financial reports; $25 \%$ environmental reports; and only $16.7 \%$ sustainability reports (only half of them say that they use the guidelines of Global Reporting Initiatives (GRI), while the others do not know whether they follow these guidelines or not). Only $8.3 \%$ of the corporations under study have a publicly available code of ethics. There are also other ways of communicating with stakeholders about the socially responsible activities that corporations perform: in $33.3 \%$ of corporations, there are no external communications with stakeholders; $26.7 \%$ use informal company presentations; and, in another $26.6 \%$, the company website has been used as the facilitator of communications. Twenty per cent of corporations allow external rating agencies to rate their sustainability performance, whilst $13.3 \%$ communicate with socially responsible investors.

From the survey, it is evident that $85 \%$ of corporations do not provide public information on the issue of executive remuneration - which is standard in integrated reports in developed countries. This therefore raises many questions concerning the harmonisation of reporting standards in Croatian companies with those of developed countries as a means of starting to catch up with their counterparts.

The overall results show that, with regard to corporate reporting (especially sustainability reporting), Croatian corporations lag behind their counterparts from developed countries in the European Union and the USA. Nevertheless, it should not be forgotten that the Republic of Croatia has been passing through a dynamic transition process and is still adjusting to the so-called rules of the free market economy. Thus, it is good to know that, among the surveyed corporations, there are those companies which publish environmental and sustainability reports, as well as those which have been evaluated by different external evaluators. Corporation websites are a good media for delivering information to internal and external stakeholders, and it is extremely important that this has been recognised among Croatian corporations.

\section{Final remarks}

The challenges that corporations face today have an important influence on corporate governance. The trends are changing due to new demands imposed by various stakeholders and the dramatic changes arising from globalisation processes, technological change, demographic shifts, climate change, etc. These changes have created an atmosphere in which corporations, in order to succeed and to be accepted by different stakeholders, need to change their usual ways of reporting. The focus should not be put solely on financial disclosure (annual financial reports); in contrast, integrated reporting provides a new step in the developing arena of corporate reporting. Published for the first time in developed countries in 2009, integrated reports are supposed to be 'a standard' by 2012. Developing and transition countries still very much lag behind, being focused mostly on financial disclosure. 
Nevertheless, the survey that we have conducted in the Republic of Croatia has revealed some very interesting points. Croatian corporations mostly disclose just financial information, but they are also starting to recognise that sustainability reports and environmental reports are a very decent way of communicating with internal and external stakeholders if they are to be accepted by them. Even more interesting is that, amongst the surveyed corporations, $20 \%$ of them have been evaluated by external rating agencies (in terms of their sustainability performance).

There have been no previous studies focused on this particular aspect of corporate communications, so it is not possible to compare the results with a previous period. Hence, it would be good to focus our future analysis on these particular issues, so as to gather information which could be comparable with these results and thus reveal the evolving trends in the Republic of Croatia.

\section{References}

Adams, C (2004) 'Ethical, social and environmental reporting' Accounting, Auditing \& Accountability Journal 17(5): 731-757.

Buchanan, D. A and A. A. Huczynski (2010) Organisational behaviour Pearson Education Limited 7th edition: Edinburgh, Scotland.

Chambers, T (2003) 'Value reporting: a bigger, more accurate picture than traditional financial reporting' Ivey Business Journal 67(6): 1-5.

Coombes, P and S. Wong (2004) Investor perspectives on corporate governance - a rapidly evolving story McKinsey \& Company, Inc.

DiPiazza, S. A and R. G. Eccles (2002) The Future of Corporate Reporting: Building Public Trust, Concentrated Knowledge for Busy Executives Vol. 24 No. 12 Part 2, December.

Eccles, R. G and M. P. Krzus (2010) One Report. Integrated Reporting for a Sustainable Strategy John Wiley \& Sons Inc: Hoboken, NJ.

Everingham, G and S. Kana (2008) Corporate reporting JUTA and Co. Ltd., 8th edition: Lansdowne.

Koričan, M and M. Ćorić (2009) 'Korporativno upravljanje u hrvatskim tvrtkama' ZŠEM revija 3-4: 108-120.

McShane, S. L and M. A. von Glinow (2005) Organisational behaviour: emerging realities for the workplace revolution McGraw-Hill: Irwin, USA.

Owen, D. L and B. O'Dwyer (2009) 'Social Responsibility. The Reporting and Assurance Dimension' in: Crane et al. (Eds.) The Oxford Handbook of Corporate Social Responsibility Oxford University Press: Oxford.

Pervan, I (2007) Financial Reporting for Croatian Listed Companies - Need for Harmonization with EU Regulation

http://oliver.efri.hr/ euconf/2007/docs/Session9/Pervan.pdf [last accessed 26 August 2010]. 
Roberts, R. W (1992) 'Determinants of corporate social responsibility disclosure: an application of stakeholder theory' Accounting, Organizations and Society 17(6): 595-612.

Subhasis, R and D. Subhrajyoti (2009) 'Corporate Reporting Framework (CRF): Benchmarking Tata Motors Against AB Volvo and Exploring Future Challenges' Decision 36(1): 101-130.

Republic of Croatia (2007) Official Gazette 109.

Corporate Register (2010) CR Reporting Awards '10: Global Winners and Reporting Trends, CR.com.

KPMG (2008) International Survey of Corporate Responsibility Reporting 2008 KPMG International.

KPMG (2010) Integrated reporting: closing the loop of strategy KPGM International.

PricewaterhouseCoopers (2010): 'Accounting for sustainability, governance and corporate reporting' World Watch Issue 2.

PricewaterhouseCoopers website: http://www.corporatereporting.com/corporate-reporting-defined.html [last accessed 11 July 2010)

PricewaterhouseCoopers (nd) Integrated Reporting Corporate Governance Series King's Counsel. See more at:

http://www.sustainabilitysa.org/LinkClick.aspx?fileticket=j1_hLI3y2tQ $\% 3 d \&$ tabid=237 [last accessed 13 February 2011].

Responsible Investor website: http:/www.responsible-investor.com/home/article/responsible_investors_at_heart_of_new_integrated/ (site subscribers only).

The dictionary of sustainable management: Corporate reporting taken from http:// www.sustainabilitydictionary.com [last accessed 25 August 2010).

Zagreb Stock Exchange (2010) Code of Corporate Governance

http://www.zse.hr/default.aspx?id=97 [last accessed 28 August 2010].

Zagreb Stock Exchange (2011) Zagreb Stock Exchange Rules

http://www.zse.hr/default.aspx?id=97 [last accessed 28 August 2010, and subsequently updated]. 